\title{
Distinguishing Between Keto-Enol and Acid- Base Forms of Firefly Oxyluciferin Through Calculation of Excited-State Equilibrium Constants
}

\author{
Olle Falklöf and Bo Durbeej \\ Linköping University Post Print
}

Tweet

N.B.: When citing this work, cite the original article.

Original Publication:

Olle Falklöf and Bo Durbeej, Distinguishing Between Keto-Enol and Acid-Base Forms of Firefly Oxyluciferin Through Calculation of Excited-State Equilibrium Constants, 2014, Journal of Computational Chemistry, (35), 30, 2184-2194.

http://dx.doi.org/10.1002/jcc.23735

Copyright: Wiley: 12 months http://eu.wiley.com/WileyCDA/

Postprint available at: Linköping University Electronic Press

http://urn.kb.se/resolve?urn=urn:nbn:se:liu:diva-112610 


\title{
Distinguishing Between Keto-Enol and Acid-Base Forms of Firefly Oxyluciferin through Calculation of Excited-State Equilibrium Constants
}

\author{
Olle Falklöf and Bo Durbeej*
}

Division of Computational Physics, IFM, Linköping University, SE-581 83 Linköping, Sweden 


\begin{abstract}
While recent years have seen much progress in the elucidation of the mechanisms underlying the bioluminescence of fireflies, there is to date no consensus on the precise contributions to the light emission from the different possible forms of the chemiexcited oxyluciferin $\left(\mathrm{OxyLH}_{2}\right)$ cofactor. Here, this problem is investigated by the calculation of excited-state equilibrium constants in aqueous solution for keto-enol and acid-base reactions connecting six neutral, mono-anionic and di-anionic forms of $\mathrm{OxyLH}_{2}$. Particularly, rather than relying on the standard Förster equation and the associated assumption that entropic effects are negligible, these equilibrium constants are for the first time calculated in terms of excited-state free energies of a Born-Haber cycle. Performing quantum chemical calculations with density functional theory methods and using a hybrid cluster-continuum approach to describe solvent effects, a suitable protocol for the modeling is first defined from benchmark calculations on phenol. Applying this protocol to the various $\mathrm{OxyLH}_{2}$ species and verifying that available experimental data (absorption shifts and ground-state equilibrium constants) are accurately reproduced, it is then found that the phenolate-keto-OxyLH ${ }^{-}$mono-anion is intrinsically the preferred form of $\mathrm{OxyLH}_{2}$ in the excited state, which suggests a potential key role for this species in the bioluminescence of fireflies.
\end{abstract}

\title{
Keywords
}

- Light emission - Tautomerism - Protonation state - Born-Haber cycle - Density functional theory 


\section{Graphical Table of Contents}

Aqueous keto-enol and acid-base excited-state equilibrium constants between six neutral, mono-anionic and di-anionic forms of oxyluciferin, the cofactor responsible for the bioluminescence of firefly luciferase, are for the first time calculated from free energies of a Born-Haber cycle, rather than using the Förster equation. Thereby, it is found that the phenolate-keto-OxyLH ${ }^{-}$mono-anion is the preferred excited-state form of oxyluciferin in aqueous solution, attributing a potential key role to this species in the bioluminescence of fireflies.

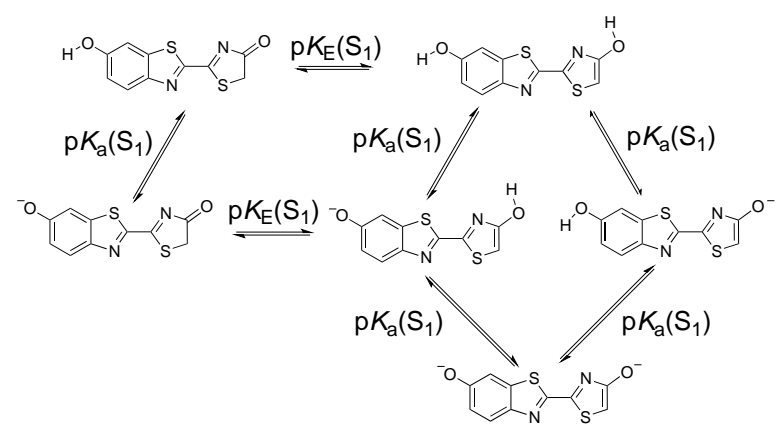




\section{Introduction}

Bioluminescence is the process by which living organisms produce cold light through chemical reactions. This phenomenon has been observed in a wide range of different phyla, and is used by the organisms primarily for communication purposes. ${ }^{[1-5]}$ Since the quantum yields of these processes enable light-based detection of molecules at low concentrations, ${ }^{[6]}$ bioluminescent reaction systems are also used in bioanalytical applications for monitoring gene expression, protein localization and protein-protein interactions. ${ }^{[7-9]}$ One bioluminescent reaction system with a particularly high quantum yield is that of fireflies, ${ }^{[10]}$ which has been the topic of many recent experimental and theoretical studies. ${ }^{[1-19]}$ However, despite that much progress has been made in the elucidation of the mechanisms underlying the light emission of fireflies, ${ }^{[11-19]}$ many details of the luciferase-catalyzed formation of the chemiexcited $\left(S_{1}\right.$, first excited singlet state) oxyluciferin emitter $\left(\mathrm{OxyLH}_{2}\right)$ from D-luciferin $\left(\mathrm{LH}_{2}\right.$, a ground-state species), are yet to be resolved. As shown in Figure 1 and described in detail elsewhere, ${ }^{[20,21]}$ this conversion is initiated by adenylation of $\mathrm{LH}_{2}$ with ATP- $\mathrm{Mg}^{2+}$, which forms D-luciferyladenylate ( $\left.\mathrm{LH}_{2}-\mathrm{AMP}\right)$. Thereafter, a dioxetanone (Diox) intermediate is generated by the oxidation of $\mathrm{LH}_{2}-\mathrm{AMP}$ with $\mathrm{O}_{2}$, followed by removal of the AMP group. Finally, Diox decomposes and the chemiexcited, visible-light-emitting $\mathrm{OxyLH}_{2}$ product is formed alongside $\mathrm{CO}_{2}$.

While Figure 1 depicts $\mathrm{OxyLH}_{2}$ in its keto form, there are (in aqueous solution) a number of co-existing and spectrally overlapping $\mathrm{OxyLH}_{2}$ forms, shown in Figure 2, that may contribute to the in vivo emission. ${ }^{[18,22,23]}$ In acidic aqueous solutions, the neutral keto $\left(\mathrm{keto}-\mathrm{OxyLH}_{2}\right)$ and enol $\left(\mathrm{enol}-\mathrm{OxyLH}_{2}\right)$ tautomers are the dominant forms. ${ }^{[18]}$ However, upon increasing the $\mathrm{p} H$, deprotonation of the hydroxyl group of keto-Oxy $\mathrm{LH}_{2}$ comes into play, which yields the phenolate-keto-OxyLH $\mathrm{LH}^{-}$mono-anion, as does deprotonation of either or both hydroxyl groups of enol- $\mathrm{OxyLH}_{2}$. Deprotonation of the enolic hydroxyl group of this species produces the enolate-OxyLH $\mathrm{LH}^{-}$mono-anion, whereas deprotonation of the phenolic hydroxyl group produces the phenolate-enol-OxyLH ${ }^{-}$ mono-anion (that exists in a tautomeric equilibrium with the phenolate-keto-OxyLH ${ }^{-}$ 
mono-anion). Deprotonation of both hydroxyl groups of enol-OxyLH 2 , in turn, yields the $\mathrm{OxyL}^{2-}$ di-anion prevalent in basic aqueous solutions. ${ }^{[18]}$

To date, there is no consensus on the precise contributions to the in vivo emission from the different forms of $\mathrm{OxyLH}_{2}$. Although there are both experimental and computational data available favoring the view that the light emitter emanates from the enzymatic reaction in the neutral keto-OxyLH $\mathrm{H}_{2}$ form, ${ }^{[16]}$ a quantum chemical study by Lindh and co-workers ${ }^{[24]}$ found that only anionic species emit in the 530-640 $\mathrm{nm}$ range where the experimental emission occurs. ${ }^{[25]}$ Furthermore, while both computational $^{[12,24,26]}$ and spectroscopic ${ }^{[27-29]}$ studies have proposed that the in vivo emission originates primarily from the phenolate-keto-OxyLH ${ }^{-}$mono-anion, Naumov and co-workers ${ }^{[14]}$ have recently studied an $\mathrm{OxyLH}_{2}$ analogue $(\mathrm{HOxyLH})$ in solution, and recorded time-resolved emission spectra favoring either of the enolate forms (enolate$\mathrm{OxyLH}^{-}$or $\mathrm{OxyL}^{2-}$ ). This result supports earlier spectroscopic work on O-methylated ether derivatives. ${ }^{[30]}$

One approach to help deducing the most probable form of the chemiexcited $\mathrm{OxyLH}_{2}$ light emitter is to measure or calculate the ground and/or excited-state equilibrium constants for the keto-enol and acid-base reactions connecting the various species of Figure 2 in solution. While it is clear that the protein environment surrounding $\mathrm{OxyLH}_{2}$ in firefly luciferase is different from, e.g., an aqueous solution, such data reveal the intrinsic tendency of $\mathrm{OxyLH}_{2}$ to prefer a particular tautomeric form and a particular protonation state, and have been reported in a number of studies..$^{[18,22,23,31-35]}$ For example, ground-state $\mathrm{p} K_{\mathrm{a}}$ measurements in water have shown that the enolic hydroxyl group of enol-OxyLH$H_{2}$ is more acidic than the phenolic hydroxyl group, ${ }^{[18]}$ which may indicate that the enolate-OxyLH ${ }^{-}$mono-anion is a likelier emitter than the phenolate-enol$\mathrm{OxyLH}^{-}$mono-anion. However, it is important to point out that $\mathrm{OxyLH}_{2}$ is more acidic in the excited state than in the ground state (i.e., $\mathrm{OxyLH}_{2}$ is a photoacid), ${ }^{[34]}$ and that the equilibrium constants between the various forms therefore may be substantially different in the two states.

The short lifetime $(\sim 1-10 \mathrm{~ns})^{[23]}$ of the $\mathrm{S}_{1}$ state makes it difficult to measure the excited-state equilibrium constants of $\mathrm{OxyLH}_{2}$ as accurately as the corresponding ground-state values. In this light, computational methods ${ }^{[36-41]}$ offer an alternative 
approach to available experimental techniques, which typically employ a Förster-type analysis $^{[42,43]}$ of differences in absorption and/or fluorescence energies between, e.g., the acid and its conjugate base. This type of analysis can also form the basis for the calculation of excited-state equilibrium constants, and has indeed been used for the $\mathrm{OxyLH}_{2}$ system in detailed studies considering vertical excitation energies in solvents with different dielectric constants. ${ }^{[32,33]}$ Inherent in such an approach is the neglect of geometric relaxation effects and the assumption that entropic contributions to the ketoenol and acid-base reactivity are identical in the ground state and the excited state. However, it is not uncommon for photoacids to exhibit excited-state potential energy surfaces that are qualitatively different from their ground-state counterparts. This may lead to poor agreement between the equilibrium constants predicted by the Förster equation and those derived in a more rigorous fashion by explicit computation of excitedstate free energies of a Born-Haber (BH) cycle. ${ }^{[44,45]}$

Another potential source of concern in the way excited-state equilibrium constants have been calculated in previous studies of the $\mathrm{OxyLH}_{2}$ system ${ }^{[32,33]}$ is the omission of explicit solvent molecules in the modeling of solute-solvent interactions, whereby especially hydrogen bonding can be poorly described. Indeed, several benchmarks exploring the methodological requirements for reliable estimation of equilibrium constants of organic molecules have highlighted the importance of explicit solvation. ${ }^{[46-}$ 50]

As a contribution to current efforts to determine the most probable chemical form of the light emitter of firefly, ${ }^{[12,14,15,18,24]}$ this work reports excited-state keto-enol and acid-base equilibrium constants for $\mathrm{OxyLH}_{2}$ in aqueous solution calculated from a $\mathrm{BH}$ cycle rather than from the Förster equation, using a hybrid cluster-continuum approach ${ }^{[46-}$ ${ }^{50]}$ to model solute-solvent interactions both implicitly and explicitly. Thereby, we are able to obtain what we believe are currently the most reliable estimates of these equilibrium constants available. Besides being valuable in their own right by disclosing the intrinsic tendency of $\mathrm{OxyLH}_{2}$ to prefer one light-emitting state over another, such data are also a prerequisite for understanding, through future experiments or calculations, how the luciferase protein modulates the excited-state equilibria between the different 
$\mathrm{OxyLH}_{2}$ forms. Although a full investigation along those lines is beyond the scope of the present work, some preliminary calculations toward this goal are also reported.

Finally, through a comparison with calculations performed using a number of different protocols based on the Förster equation, we furthermore present useful benchmark data on how the two approaches (Förster and BH) compare with each other when applied to a system of widespread photobiological interest.

\section{Computational Details}

\section{General}

Ground and excited-state equilibrium constants for the keto-enol $\left(K_{\mathrm{E}}\right)$ and acid-base $\left(K_{\mathrm{a}}\right)$ reactions of Figure 2 were determined in aqueous solution at $25^{\circ} \mathrm{C}$ based on density functional theory (DFT) calculations carried out with the GAUSSIAN 09 program. ${ }^{[51]}$ Throughout this work, these constants are expressed in terms of their negative logarithms $\mathrm{p} K_{\mathrm{E}}$ and $\mathrm{p} K_{\mathrm{a}}$, respectively.

\section{Model systems}

The calculations on the various $\mathrm{OxyLH}_{2}$ species considered the stereoisomeric forms shown in Figure 2. As an aside, these are also relevant for the protein-bound state. ${ }^{[13,52]}$ However, since a number of other stereoisomers are likely to be accessible at $25^{\circ} \mathrm{C}$, the propriety of this single-stereoisomer strategy was assessed in a series of benchmark calculations invoking Boltzmann averaging over all possible stereoisomers. Investigating all reactions of Figure 2 and using a number of different levels of theory (as further detailed below), but focusing exclusively on ground-state $\mathrm{p} K_{\mathrm{E}}$ and $\mathrm{p} K_{\mathrm{a}}$ values, these benchmark calculations found that the single-stereoisomer $\mathrm{p} K$ values differ from the Boltzmann-averaged ones by a few tenths of a $\mathrm{p} K$ unit only. Thus, for the purpose of the present study, Boltzmann averaging over several stereoisomers does not seem necessary.

Solute-solvent interactions were modeled by means of a hybrid cluster-continuum approach. ${ }^{[46-50]}$ Thereby, bulk electrostatic solvent effects were treated with the solvation model density (SMD) $)^{[53]}$ method, with the water dielectric constant $(\varepsilon)$ set to 78.4, whereas specific interactions such as hydrogen bonds were simulated by including 
explicit water molecules in the calculations. The same number of water molecules (11, as further motivated below) was consistently used for all keto-enol and acid-base equilibria under study. Placing water molecules in proximity to each of the two solute oxygen atoms, starting models of the various $\mathrm{OxyLH}_{2}$-water clusters were derived from previous computational studies of phenol-water, phenolate-water and hydroxide-water clusters. ${ }^{[54-}$ ${ }^{56]}$ One such starting model is shown in Figure 3.

\section{Calculation of $\mathrm{p} K$ values}

Using a $\mathrm{BH}$ cycle, $\mathrm{p} K$ values in the ground $\mathrm{S}_{0}$ state $\left[\mathrm{p} K^{\mathrm{BH}}\left(\mathrm{S}_{0}\right)\right]$ and the excited $\mathrm{S}_{1}$ state $\left[\mathrm{p} K^{\mathrm{BH}}\left(\mathrm{S}_{1}\right)\right]$ were obtained by calculating, in aqueous solution, standard (1 M) Gibbs free energies $\left(G^{\circ}\right)$ for reactants (ketones/acids) and products (enols/bases) in the two states, respectively. Then

$$
\mathrm{p} K^{\mathrm{BH}}\left(\mathrm{S}_{\mathrm{n}}\right)=\frac{\Delta G\left(\mathrm{~S}_{\mathrm{n}}\right)}{R T \ln 10}
$$

where $\Delta G^{\circ}$ is the reaction free energy. For each species, the free energy in aqueous solution was determined as the sum of the gas-phase free energy and the solvation free energy. Assuming ideal-gas behavior and employing the harmonic approximation, the gas-phase free energy was calculated as the sum of the electronic energy and the thermal free energy (obtained from a frequency calculation) at the gas-phase geometry. Using the SMD continuum solvation model, ${ }^{[53]}$ the solvation free energy, in turn, was calculated at the solution-phase geometry as the difference in electronic energy in aqueous solution and the electronic energy in the gas phase.

As for the estimate of the proton's Gibbs free energy needed for the $\mathrm{p} K_{\mathrm{a}}$ calculations, a value of $-272.2 \mathrm{kcal} \mathrm{mol}^{-1}$ was inferred from standard values in the literature of the proton's gas-phase $\left(-6.28 \mathrm{kcal} \mathrm{mol}^{-1}\right)$ and solvation $\left(-265.9 \mathrm{kcal} \mathrm{mol}^{-1}\right)$ free energies. ${ }^{[57,58]}$

In addition to determining absolute excited-state $\mathrm{p} K$ values from a $\mathrm{BH}$ cycle, we also calculated $\Delta \mathrm{p} K\left(\mathrm{~S}_{1}\right)$ values probing the difference in excited-state and ground-state equilibrium constants using the Förster equation ${ }^{[42]}$ 


$$
\Delta \mathrm{p} K\left(\mathrm{~S}_{1}\right)=\mathrm{p} K\left(\mathrm{~S}_{1}\right) \quad \mathrm{p} K\left(\mathrm{~S}_{0}\right) \frac{\Delta \Delta E}{R T \ln 10}
$$

In its simplest incarnation, this equation considers vertical electronic transition energies $\Delta E$ between the two states in aqueous solution, and then expresses $\Delta \mathrm{p} K\left(\mathrm{~S}_{1}\right)$ in terms of the difference $\Delta \Delta E$ between the vertical transition energy of the product (enol/base) and the vertical transition energy of the reactant (ketone/acid). Thereby, geometric relaxation effects and entropic contributions are neglected. Here, five different Förster protocols were employed. In the first and second, vertical excitation energies based on optimized ground-state geometries and vertical emission energies based on optimized excited-state geometries were calculated to yield $\Delta \mathrm{p} K\left(\mathrm{~S}_{1}\right)$ values denoted $\Delta \mathrm{p} K^{\mathrm{F}, \operatorname{exc}}\left(\mathrm{S}_{1}\right)$ and $\Delta \mathrm{p} K^{\mathrm{F}, \mathrm{emi}}\left(\mathrm{S}_{1}\right)$, respectively. In the third, the average of these two values [denoted $\Delta \mathrm{p} K^{\mathrm{F} \text {,exc+emi }}\left(\mathrm{S}_{1}\right)$ ] was considered. In the fourth, adiabatic excitation energies obtained as energy differences between excited states and ground states at their respective equilibrium geometries formed the basis for the calculation of $\Delta \mathrm{p} K\left(\mathrm{~S}_{1}\right)$ values denoted $\Delta \mathrm{p} K^{\mathrm{F}, \text { adia }}\left(\mathrm{S}_{1}\right)$. In the fifth and final protocol, adiabatic excitation energies including zero-point vibrational energy (ZPVE) corrections to each state were calculated to yield $\Delta \mathrm{p} K\left(\mathrm{~S}_{1}\right)$ values denoted $\Delta \mathrm{p} K^{\mathrm{F}, 0-0}\left(\mathrm{~S}_{1}\right)$.

\section{Electronic structure level of theory}

Ground and excited-state species were treated with DFT and time-dependent DFT (TDDFT), ${ }^{[59-64]}$ respectively. Six global hybrid or long-range-corrected hybrid functionals including B3LYP, ${ }^{[65-67]}$ M06 ${ }^{[68]}$ (global hybrids), LC-BLYP, ${ }^{[69]}$ CAM-B3LYP, ${ }^{[70]}$ $\omega \mathrm{B} 97 \mathrm{X}^{[71]}$ and $\omega \mathrm{B} 97 \mathrm{X}-\mathrm{D}^{[72]}$ (long-range-corrected hybrids) were employed. While global hybrids contain a fixed fraction of exact Hartree-Fock (HF) exchange, long-rangecorrected hybrids allow the fraction of exact exchange to vary with the interelectronic distance (larger at long range), which typically offers a better description of chargetransfer states. In addition to DFT and TD-DFT calculations, supplementary calculations were for comparative purposes also performed using HF theory for ground states and the configuration interaction singles (CIS) method for excited states. 
All ground and excited-state geometry optimizations were carried out in the gas phase or in aqueous solution using analytic DFT and TD-DFT gradients, ${ }^{[73-77]}$ respectively. To ascertain that optimized geometries correspond to potential energy minima and to calculate ZPVE corrections and thermal free energies, frequency calculations were performed at the same levels of theory as the preceding geometry optimizations. While the DFT and HF frequency calculations were executed with analytic Hessians, the TD-DFT frequency calculations were carried out numerically using finite differences. ${ }^{[78,79]}$ The latter were the most resource-demanding calculations of this work, requiring up to 330 distorted geometries to be considered for each potential energy minimum. The CIS frequency calculations, finally, were done with analytic Hessians in the gas phase, but numerically in aqueous solution.

As for basis sets, all geometry optimizations, frequency calculations and singlepoint calculations (of vertical transition energies) were done with the $6-31+G(d, p)$ double- $\zeta$ basis set, which includes diffuse functions for second-row atoms. To assess the magnitude of basis-set effects, singlepoint calculations were in a number of cases also performed with the larger aug-cc-pVTZ triple- $\zeta$ basis set.

The excited-state singlepoint calculations with the SMD continuum solvation mode ${ }^{[53]}$ were carried out with so-called non-equilibrium solvation, whereby only the electronic ("fast") degrees of freedom of the solvent have time to respond to the change in electronic state of the solute. The corresponding excited-state geometry optimizations and frequency calculations, on the other hand, were carried out in the equilibrium regime, with relaxation also of the solvent nuclear ("slow") degrees of freedom.

Finally, it should be noted that a potentially weak point in calculating $\mathrm{p} K$ values from Eq. 1 by exclusively considering water-solvated $\mathrm{OxyLH}_{2}$ complexes at their ground and excited-state potential energy minima is the assumption that frequency calculations give accurate free energies in this context. However, this assumption is complicated by the fact that the water molecules attached to $\mathrm{OxyLH}_{2}$ are labile, and as such will make an entropy contribution to the free energy that would be better dealt with using free-energy perturbation techniques and molecular dynamics simulations. ${ }^{\left[{ }^{80]}\right.}$ Unfortunately, at present, such calculations are not really feasible for excited-state problems. 


\section{Results and Discussion}

\section{Benchmark calculations on phenol}

In order to identify a suitable way of modeling the $\mathrm{OxyLH}_{2}$ system with respect to explicit solvation and quantum chemical level of theory, we will first discuss the results of a series of benchmark calculations on phenol, which is a prototypical photoacid. ${ }^{[43,81]}$ Furthermore, phenol is also an appropriate benchmark molecule in that many of the acidbase reactions of $\mathrm{OxyLH}_{2}$ involve a phenol/phenolate moiety.

Starting with explicit solvation, the importance of which has been raised in a number of previous studies dealing with the calculation of $\mathrm{p} K_{\mathrm{a}}$ values of organic molecules, ${ }^{[46-50]}$ it is first and foremost of interest to explore how many water molecules are needed to obtain stable estimates of the ground and excited-state $\mathrm{p} K_{\mathrm{a}}$ values of phenol. To this end, these values were calculated for a varying number of water molecules, as shown in Figure 4 ( $\omega$ B97X-D results) and Figures S1-S4 (other functionals) of the Supporting Information (SI). Since all functionals support the same overall trend, it suffices to note from Figure 4 that reasonably well-converged $\mathrm{p} K_{\mathrm{a}}{ }^{\mathrm{BH}}\left(\mathrm{S}_{0}\right)$ and $\mathrm{p} K_{\mathrm{a}}{ }^{\mathrm{BH}}\left(\mathrm{S}_{1}\right)$ values seem to require the inclusion of at least five water molecules in the calculations. In this regard, it is important to point out that the attainment of convergence to within, say, $\sim 2 \mathrm{p} K$ units or better is rendered difficult by the fact that even a minor error of $1 \mathrm{kcal}$ $\mathrm{mol}^{-1}$ in free energy shifts the equilibrium constants by close to $1 \mathrm{p} K$ unit. On the other hand, estimating the difference $\Delta \mathrm{p} K_{\mathrm{a}}{ }^{\mathrm{BH}}\left(\mathrm{S}_{1}\right)$ between $\mathrm{p} K_{\mathrm{a}}{ }^{\mathrm{BH}}\left(\mathrm{S}_{1}\right)$ and $\mathrm{p} K_{\mathrm{a}}{ }^{\mathrm{BH}}\left(\mathrm{S}_{0}\right)$, which is a central goal of this work, is much less demanding in terms of explicit solvation than estimating the absolute values of $\mathrm{p} K_{\mathrm{a}}{ }^{\mathrm{BH}}\left(\mathrm{S}_{1}\right)$ and $\mathrm{p} K_{\mathrm{a}}{ }^{\mathrm{BH}}\left(\mathrm{S}_{0}\right)$ individually. Indeed, the $\Delta \mathrm{p} K_{\mathrm{a}}{ }^{\mathrm{BH}}\left(\mathrm{S}_{1}\right)$ values that can be extracted from Figure 4 are quite well-converged already for two water molecules.

Continuing with a comparison of how well different density functionals reproduce the experimental ground and excited-state $\mathrm{p} K_{\mathrm{a}}$ values of phenol, the corresponding results are summarized in Table 1. As for the experimental reference data, a ground-state value of $10.00 \mathrm{pK}$ units has been determined using titration techniques. ${ }^{[81]}$ The excited-state value, ${ }^{[43]}$ on the other hand, has been determined from absorption and fluorescence data through the Förster equation. Thereby, it was found that the excited state is $6.00 \mathrm{p} K$ units 
more acidic than the ground state. ${ }^{[43]}$ To allow for a balanced comparison with this reference value, Table 1 presents calculated $\Delta \mathrm{p} K_{\mathrm{a}}^{\mathrm{F}}{ }^{\mathrm{F}, \mathrm{exc}+\mathrm{emi}}\left(\mathrm{S}_{1}\right)$ - rather than $\mathrm{p} K_{\mathrm{a}}{ }^{\mathrm{BH}}\left(\mathrm{S}_{1}\right)-$ values (see also discussion in the Computational Details section).

For the ground state, it can be seen from Table 1 that the experimental value of $10.00 \mathrm{pK}$ units is best matched by B3LYP (9.86) and $\omega \mathrm{B} 97 \mathrm{X}-\mathrm{D}$ (9.60), but also that all functionals except LC-BLYP (6.32) have errors that are smaller than $2 \mathrm{p} K$ units. For the excited state, the situation is similar. Indeed, all functionals are within $2 \mathrm{p} K$ units from the experimental $\Delta \mathrm{p} K_{\mathrm{a}}^{\mathrm{F}, \text { exc+emi }}\left(\mathrm{S}_{1}\right)$ value of -6.00 , with B3LYP (-7.29) and $\omega \mathrm{B} 97 \mathrm{X}-\mathrm{D}(-$ 7.12) again among the best performers. Overall, the accuracy with which the present DFT-based calculations reproduce the ground and excited-state $\mathrm{p} K_{\mathrm{a}}$ values of phenol seems to support the application of such calculations to the related $\mathrm{OxyLH}_{2}$ system, although the results may appear more accurate than what the methodology allows for because of cancellation of errors.

We also performed complementary calculations addressing the difference in acidity between the ground and excited states of phenol in further detail. However, rather than using the experimental $\Delta \mathrm{p} K_{\mathrm{a}}^{\mathrm{F}, \text { exc }+ \text { emi }}\left(\mathrm{S}_{1}\right)$ value of -6.00 as reference, we tested how well the current methodology reproduces the experimental $\Delta \mathrm{p} K_{\mathrm{a}}{ }^{\mathrm{F}, \mathrm{exc}}\left(\mathrm{S}_{1}\right)$ and $\Delta \mathrm{p} K_{\mathrm{a}}{ }^{\mathrm{F}, \mathrm{emi}}\left(\mathrm{S}_{1}\right)$ values that can also be extracted (through alternative Förster protocols) from the absorption and fluorescence data of Wehry and Rogers. ${ }^{[33]}$ These calculations are summarized in Table 2, and focus on the performance of the three methods - B3LYP, $\omega \mathrm{B} 97 \mathrm{X}$ and $\omega \mathrm{B} 97 \mathrm{X}-\mathrm{D}$ - that yielded the most accurate estimates of $\mathrm{p} K_{\mathrm{a}}{ }^{\mathrm{BH}}\left(\mathrm{S}_{0}\right)$ and $\Delta \mathrm{p} K_{\mathrm{a}}^{\mathrm{F}}{ }^{\mathrm{F} e x c+e m i}\left(\mathrm{~S}_{1}\right)$. The corresponding M06, LC-BLYP, CAM-B3LYP and HF/CIS results are collected in Table S1 of the SI. For the sake of completeness, Table 2 also includes calculated $\Delta \mathrm{p} K_{\mathrm{a}}^{\mathrm{F}, \text { adia }}\left(\mathrm{S}_{1}\right)$ and $\Delta \mathrm{p} K_{\mathrm{a}}^{\mathrm{F}, 0-0}\left(\mathrm{~S}_{1}\right)$ Förster and $\Delta \mathrm{p} K_{\mathrm{a}}{ }^{\mathrm{BH}}\left(\mathrm{S}_{1}\right)$ BH values, albeit that these lack experimental counterparts.

Encouragingly, it is observed from Table 2 that the B3LYP, $\omega B$ 97X and $\omega B$ 97XD estimates of $\Delta \mathrm{p} K_{\mathrm{a}}^{\mathrm{F}, \text { exc }}\left(\mathrm{S}_{1}\right)$ and $\Delta \mathrm{p} K_{\mathrm{a}}^{\mathrm{F}, \text {,emi }}\left(\mathrm{S}_{1}\right)$ are just as accurate as the corresponding estimates of $\Delta \mathrm{p} K_{\mathrm{a}}^{\mathrm{F}}$,exc+emi $\left(\mathrm{S}_{1}\right)$, with errors relative to experimental values that throughout (but somewhat fortuitously) are smaller than $1.7 \mathrm{pK}$ units. As far as this test is concerned, then, it is difficult to distinguish which of these functionals is the preferred choice of methodology for the $\mathrm{OxyLH}_{2}$ system. Nonetheless, it was decided to perform the 
$\mathrm{OxyLH}_{2}$ calculations using $\omega \mathrm{B} 97 \mathrm{X}-\mathrm{D}$, which includes dispersion ${ }^{[72]}$ and is better able to describe long-range charge-transfer effects. ${ }^{[82]}$

Finally, it is also of interest to compare the $\Delta \mathrm{p} K_{\mathrm{a}}\left(\mathrm{S}_{1}\right)$ Förster values with the $\Delta \mathrm{p} K_{\mathrm{a}}\left(\mathrm{S}_{1}\right) \mathrm{BH}$ values without reference to experimental data. In fact, since the $\mathrm{BH}$ values require more elaborate calculations (particularly numerical frequency calculations to obtain excited-state free energies), good agreement between the Förster and $\mathrm{BH}$ values may be an indication that the subsequent modeling of the $\mathrm{OxyLH}_{2}$ equilibria can be simplified. From this comparison in Table 2, there seems to be some grounds for optimism in this regard, because all types of Förster values except those based on vertical emission energies [i.e., $\left.\Delta \mathrm{p} K_{\mathrm{a}}^{\mathrm{F}}{ }^{\mathrm{F}, \mathrm{emi}}\left(\mathrm{S}_{1}\right)\right]$ show consistently good agreement $(\sim 1.5 \mathrm{p} K$ units or better) with the $\mathrm{BH}$ values.

\section{Assessment of the Förster approach for $\mathrm{OxyLH}_{2}$}

Having assessed the adequacy of the Förster approach for phenol, we next proceed to explore how well it applies to the $\mathrm{OxyLH}_{2}$ system. This was done using computational models including 11 explicit water molecules. The reason for including 11 waters is that, based on the benchmark calculations on phenol, it seems necessary to solvate $\mathrm{OxyLH}_{2}$ with at least ten waters (five per oxygen atom) to ensure that calculated equilibrium constants are sufficiently converged. Besides these ten waters, added to the respective $\mathrm{OxyLH}_{2}$ species as described in the Computational Details section, each cluster was further stabilized by the introduction of an additional water molecule linking the nitrogen atom of the thiazole/thiazolone ring with the neighboring water network.

Using these computational models, $\Delta \mathrm{p} K_{\mathrm{E}}\left(\mathrm{S}_{1}\right)$ and $\Delta \mathrm{p} K_{\mathrm{a}}\left(\mathrm{S}_{1}\right)$ values for all equilibria in Figure 2 were calculated with all five of the previously defined Förster protocols, and were then compared with the corresponding values calculated with the $\mathrm{BH}$ approach. This comparison is presented in Table 3, and takes the form of mean signed errors (MSEs), root-mean-square deviations (RMSDs) and maximum absolute deviations (MADs) of the Förster values relative to the $\mathrm{BH}$ values.

Notably, while each Förster protocol on average compares quite well with the $\mathrm{BH}$ approach, with RMSDs between 0.97 and $1.94 \mathrm{p} K$ units, there is at least one keto-enol or acid-base equilibrium for which every protocol deviates from the corresponding $\mathrm{BH}$ 
value by about twice as much. This is reflected by the MADs, which lie between 2.04 and $3.57 \mathrm{p} K$ units. Furthermore, as can be inferred from the observation that the MSEs are consistently smaller in magnitude $(\leq 0.59 \mathrm{p} K$ units) than the RMSDs $(\leq 1.94 \mathrm{p} K$ units), the Förster values are neither systematically larger nor systematically smaller than the $\mathrm{BH}$ reference values. For example, for the protocol based on vertical excitation energies [i.e., $\left.\Delta \mathrm{p} K^{\mathrm{F}, \text { exc }}\left(\mathrm{S}_{1}\right)\right]$, Tables $\mathrm{S} 2-\mathrm{S} 8$ of the SI show that the Förster values range from being 2.8 $\mathrm{p} K$ units smaller for one particular equilibrium constant, to being $1.4 \mathrm{p} K$ units larger for another. As for singling out one specific equilibrium constant for which the Förster values are consistently different from the $\mathrm{BH}$ value, it is found (see Table S2 of the SI) that all five protocols yield a $\Delta \mathrm{p} K_{\mathrm{E}}\left(\mathrm{S}_{1}\right)$ for the keto-OxyLH $\mathrm{H}_{2} \rightleftharpoons$ enol-OxyLH $\mathrm{H}_{2}$ reaction that is $2.0-3.1 \mathrm{p} K$ units smaller than the $\mathrm{BH}$ estimate.

Overall, then, while the Förster approach was found to perform quite well for phenol, the situation is somewhat different for $\mathrm{OxyLH}_{2}$. Indeed, the data in Table 3 indicate that this approach can potentially introduce errors by which our goal to rather use $\mathrm{BH}$-derived equilibrium constants to identify the preferred form of $\mathrm{OxyLH}_{2}$ in aqueous solution seems worthwhile. The reason why the Förster approach works better for phenol than for $\mathrm{OxyLH}_{2}$ relates, we believe, to two factors. First, as will be discussed in further detail below, the inter-ring carbon-carbon bond is for most $\mathrm{OxyLH}_{2}$ forms shortened quite appreciably in the excited state. Since phenol harbors no bond with a similar feature, this molecule should be less sensitive than $\mathrm{OxyLH}_{2}$ to the fact that most of the Förster protocols considered neglect geometric relaxation effects. Second, considering that it seems reasonable to assume that a shortening of the inter-ring bond of $\mathrm{OxyLH}_{2}$ in the excited state decreases the entropy (by virtue of reducing the molecular flexibility), phenol also appears less sensitive than $\mathrm{OxyLH}_{2}$ to the assumption in all Förster protocols that entropic effects are identical in the ground state and the excited state.

\section{Validation of the computational approach for $\mathrm{OxyLH}_{2}$}

Before exploring what insights into the excited-state equilibria of $\mathrm{OxyLH}_{2}$ that calculated $\mathrm{p} K_{\mathrm{E}}{ }^{\mathrm{BH}}\left(\mathrm{S}_{1}\right)$ and $\mathrm{p} K_{\mathrm{a}}^{\mathrm{BH}}\left(\mathrm{S}_{1}\right)$ values can offer, it is pertinent to validate our computational approach relative to relevant experimental data. In the absence of thermodynamically derived excited-state $\mathrm{p} K$ values of $\mathrm{OxyLH}_{2}$ in the experimental literature, an alternative 
set of reference data can be found in the study by Rebarz et al., ${ }^{[18]}$ who reported absorption shifts in aqueous solution between all species implicated in the keto-enol and acid-base equilibria. From Table 4, it is observed that the corresponding differences in vertical $\mathrm{S}_{0} \rightarrow \mathrm{S}_{1}$ excitation energies that our computational approach predicts are throughout very similar to their experimental counterparts. Indeed, the calculated and experimental absorption shifts agree to within $0.05 \mathrm{eV}$ for the keto-enol reactions and to within $0.12 \mathrm{eV}$ or better for the acid-base reactions. This finding indicates that $\omega \mathrm{B} 97 \mathrm{X}-$ $\mathrm{D} / 6-31+\mathrm{G}(\mathrm{d}, \mathrm{p})$ calculations on $\mathrm{OxyLH}_{2}$ models including 11 water molecules are able to reliably describe the excited-state equilibria of $\mathrm{OxyLH}_{2}$.

A further possibility for validation is provided by a few thermodynamically derived ground-state $\mathrm{p} K$ values of $\mathrm{OxyLH}_{2}$ that, contrasting with the lack of such data for the excited state, are available in the experimental literature. ${ }^{[18]}$ Clearly, it is of interest to test how well our calculations can reproduce these values. The results of this test are summarized in Table 5. Re-emphasizing the potential role played by cancellation of errors, it can be seen that the calculated values are very close to the experimental ones for two out of three equilibria. Specifically, the discrepancies are smaller than $1 \mathrm{p} K$ unit for the keto-OxyLH $\mathrm{H}_{2} \rightleftharpoons$ enol-OxyLH $\mathrm{H}_{2}$ and enolate- $\mathrm{OxyLH}^{-} \rightleftharpoons \mathrm{OxyL}^{2-}$ equilibria, but larger ( $\sim 3.4 \mathrm{pK}$ units $)$ for the enol-OxyLH $\mathrm{CH}_{2} \rightleftharpoons$ enolate-OxyLH${ }^{-}$equilibrium. Notwithstanding these results, it should be noted that the calculated $\mathrm{p} K_{\mathrm{E}}$ value for the tautomerization of keto-OxyLH $\mathrm{H}_{2}$ into enol-OxyLH $\mathrm{O}_{2}$ is of opposite sign (0.48) to the experimental value, which is of such magnitude $(-0.39)$ that, for the type of calculations here performed, it is a considerable challenge to even reproduce it with qualitative accuracy.

Further, it is possible that the calculated $\mathrm{p} K_{\mathrm{a}}$ value of 4.77 for the keto-OxyLH $\mathrm{OH}_{2} \rightleftharpoons$ phenolate-keto-OxyLH ${ }^{-}$equilibrium is somewhat off the mark, because experiments have shown that $\mathrm{OxyLH}_{2}$ is only deprotonated at $\mathrm{pH} 7$ or higher. ${ }^{[18,34]}$ On the other hand, this experimental value includes contributions from all three acid-base equilibria of the keto$\mathrm{OxyLH}_{2}$ and enol-OxyLH $\mathrm{L}_{2}$ forms (cf. Figure 2), and does not uniquely pinpoint the keto$\mathrm{OxyLH}_{2} \rightleftharpoons$ phenolate-keto-OxyLH${ }^{-}$reaction.

Overall, while we believe that the results in Table 5 underline the predictive power of our approach, it was nonetheless decided to slightly alter the procedure by which the "final" estimates of the excited-state $\mathrm{p} K$ values of $\mathrm{OxyLH}_{2}$ were obtained. This 
alteration, which reduces the impact of computational errors such as that for the enol$\mathrm{OxyLH}_{2} \rightleftharpoons$ enolate-OxyLH${ }^{-}$reaction, will be outlined in the next section.

\section{Predicting the preferred chemical form of $\mathrm{OxyLH}_{2}$}

Having validated the computational approach, we are now in position to predict the preferred chemical form of $\mathrm{OxyLH}_{2}$ in the excited state in aqueous solution from calculated $\mathrm{p} K_{\mathrm{E}}{ }^{\mathrm{BH}}\left(\mathrm{S}_{1}\right)$ and $\mathrm{p} K_{\mathrm{a}}{ }^{\mathrm{BH}}\left(\mathrm{S}_{1}\right)$ values. However, although we have reason to believe from the preceding benchmark calculations that these values, which are included in Table S9 of the SI, offer a reliable description of the excited-state reactivity of $\mathrm{OxyLH}_{2}$, we will instead base our analysis on a set of excited-state $\mathrm{p} K$ values obtained in a different way (importantly, the resulting data and the data in Table S9 sustain the same exact conclusion on the identity of the preferred $\mathrm{OxyLH}_{2}$ species). Specifically, as alluded to in the previous section and as argued also by other authors, ${ }^{[19]}$ it is to some extent possible to cancel inevitable computational errors in $\mathrm{p} K_{\mathrm{E}}{ }^{\mathrm{BH}}\left(\mathrm{S}_{1}\right)$ and $\mathrm{p} K_{\mathrm{a}}{ }^{\mathrm{BH}}\left(\mathrm{S}_{1}\right)$ by rather considering the $\mathrm{p} K^{\mathrm{BH}}\left(\mathrm{S}_{1}\right)$ values, henceforth denoted $\mathrm{p} K^{\mathrm{BH}, \text { corr }}\left(\mathrm{S}_{1}\right)$, obtained by adding calculated $\Delta \mathrm{p} K^{\mathrm{BH}}\left(\mathrm{S}_{1}\right)$ values to experimental ground-state $\mathrm{p} K$ values $\left[\mathrm{p} K^{\exp }\left(\mathrm{S}_{0}\right)\right]$

$$
\mathrm{p} K^{\mathrm{BH}, \text { corr }}\left(\mathrm{S}_{1}\right)=\mathrm{p} K^{\mathrm{exp}}\left(\mathrm{S}_{0}\right)+\Delta \mathrm{p} K^{\mathrm{BH}}\left(\mathrm{S}_{1}\right) .
$$

Of course, this is a strictly empirical approach that requires that $\mathrm{p} K^{\exp }\left(\mathrm{S}_{0}\right)$ values are available for all keto-enol and acid-base equilibria of the $\mathrm{OxyLH}_{2}$ system, which is not the case (see Table 5). However, as described in Section 14 of the SI, it is straightforward to estimate the missing values from existing experimental data, ${ }^{[18]}$ combined with an analysis of calculated $\mathrm{p} K^{\mathrm{BH}}\left(\mathrm{S}_{0}\right)$ values. These estimates are collected in Table S10 of the SI, and enable calculation of the $\mathrm{p} K^{\mathrm{BH}, \text { corr }}\left(\mathrm{S}_{1}\right)$ values presented in Figure 5.

Considering first the keto-OxyLH $\mathrm{H}_{2} \rightleftharpoons$ enol- $\mathrm{OxyLH}_{2}$ equilibrium (reaction I in Figure 5), the $\mathrm{p} K_{\mathrm{E}}{ }^{\mathrm{BH}}$,corr $\left(\mathrm{S}_{1}\right)$ of $\sim 5$ is a clear indication that the keto-OxyLH $\mathrm{H}_{2}$ form is much more stable than the enol-OxyLH $\mathrm{H}_{2}$ form in the excited state. Accordingly, it seems unlikely that the latter form is populated in the excited state in aqueous solution. This situation is different from the situation in the ground state, where the $\mathrm{p} K_{\mathrm{E}}{ }^{\exp }\left(\mathrm{S}_{0}\right)$ of -0.39 
signals that the two forms are of similar stability. Indeed, for the ground state, there are both experimental ${ }^{[14,18,22,83]}$ and computational ${ }^{[31,35]}$ data for a variety of solvents from which the presence of enol-OxyLH $\mathrm{H}_{2}$ can be inferred.

Next, we turn to the keto-OxyLH ${ }_{2} \rightleftharpoons$ phenolate-keto-OxyLH ${ }^{-}$equilibrium (reaction IV), which has a $\mathrm{p} K_{\mathrm{a}}{ }^{\exp }\left(\mathrm{S}_{0}\right)$ of $\sim 8.0$ and thus is somewhat shifted toward the keto-OxyLH $\mathrm{H}_{2}$ form in the ground state. With a $\mathrm{p} K_{\mathrm{a}}{ }^{\mathrm{BH}, \text { corr }}\left(\mathrm{S}_{1}\right)$ of $\sim 2$, on the other hand, the excited state favors the phenolate-keto-OxyLH ${ }^{-}$form. In this connection, it should be clarified that the reference conditions implicated in the interpretation of $\mathrm{p} K_{\mathrm{a}}$ values in this work correspond to a buffered aqueous solution at $\mathrm{pH} 7$, whereby a $\mathrm{p} K_{\mathrm{a}}{ }^{\mathrm{BH}, \text { corr }}\left(\mathrm{S}_{1}\right)$ of $\sim 2$ seems sufficiently decisive.

With the neutral $\mathrm{OxyLH}_{2}$ forms seemingly out of the picture as the preferred excited-state species in aqueous solution, we continue by comparing the three monoanionic forms: phenolate-keto-OxyLH ${ }^{-}$, phenolate-enol-OxyLH ${ }^{-}$and enolate-OxyLH ${ }^{-}$. First, we consider the phenolate-keto-OxyLH ${ }^{-} \rightleftharpoons$ enolate-OxyLH ${ }^{-}$equilibrium (reaction II), which corresponds to keto-enol tautomerization of phenolate-keto-OxyLH ${ }^{-}$into phenolate-enol-OxyLH ${ }^{-}$and subsequent proton transfer from the enolic hydroxyl group to the phenolate, and find that phenolate-keto-OxyLH ${ }^{-}$is a much more stable species than enolate-OxyLH ${ }^{-}$in the excited state (by $\sim 6 \mathrm{pK}$ units). This contrasts with the situation in the ground state, where enolate-OxyLH ${ }^{-}$is slightly favored (by $\sim 1 \mathrm{pK}$ unit). For the phenolate-keto-OxyLH ${ }^{-} \rightleftharpoons$ phenolate-enol-OxyLH ${ }^{-}$equilibrium (reaction III), in turn, the $\mathrm{p} K_{\mathrm{E}}{ }^{\mathrm{BH}, \mathrm{corr}}\left(\mathrm{S}_{1}\right)$ of $\sim 7$ provides similarly strong support for phenolate-keto-OxyLH ${ }^{-}$also being dominant over phenolate-enol-OxyLH ${ }^{-}$in the excited state. Hence, out of the three mono-anionic forms, only phenolate-keto-OxyLH ${ }^{-}$looks to come into play.

At this stage, the search for the preferred chemical form of $\mathrm{OxyLH}_{2}$ in the excited state in aqueous solution is narrowed down to either of two species: the phenolate-keto$\mathrm{OxyLH}^{-}$mono-anion or the $\mathrm{OxyL}^{2-}$ di-anion, which are connected by reaction VII in Figure 5. Studying an $\mathrm{OxyLH}_{2}$ analogue $(\mathrm{HOxyLH})$ in different solvents with timeresolved emission spectroscopy, this reaction, or more precisely keto-enol tautomerization of phenolate-keto-OxyLH ${ }^{-}$into phenolate-enol-OxyLH ${ }^{-}$and subsequent excited-state deprotonation, was recently implicated by Naumov and co-workers ${ }^{[14]}$ as a route by which $\mathrm{OxyL}^{2-}$ becomes a potential key species for the in vivo emission. In 
contrast to this proposal, however, the $\mathrm{p} K_{\mathrm{a}}{ }^{\mathrm{BH} \text {,corr }}\left(\mathrm{S}_{1}\right)$ of $\sim 14$ suggests that the excited-state equilibrium between phenolate-keto-OxyLH ${ }^{-}$and $\mathrm{OxyL}^{2-}$ is strongly shifted toward the former species. Hence, as far as intrinsic excited-state stability is concerned, the overall conclusion emerging from Figure 5 is that phenolate-keto-OxyLH ${ }^{-}$is the dominant species in aqueous solution, without significant contributions from the enolate-OxyLH ${ }^{-}$ and $\mathrm{OxyL}^{2-}$ forms favored by the data of Naumov and co-workers. ${ }^{[14]}$ Importantly, this conclusion, which was reached also in an earlier study employing the Förster equation and using a continuum solvation model-based description of the water solvent, ${ }^{[33]}$ appears well-founded in that it is based on a series of comparisons between possible $\mathrm{OxyLH}_{2}$ forms for which the decisive $\mathrm{p} K_{\mathrm{E}}{ }^{\mathrm{BH} \text {,corr }}\left(\mathrm{S}_{1}\right)$ and $\mathrm{p} K_{\mathrm{a}}{ }^{\mathrm{BH} \text {,corr }}\left(\mathrm{S}_{1}\right)$ values exhibit margins of at least $5 \mathrm{p} K$ units relative to the values ( 0 and 7 , respectively) that allow for no discrimination at all between the forms.

While there is a discrepancy between the present results and the results of Naumov and co-workers ${ }^{[14]}$ as to the importance of the enolate-OxyLH ${ }^{-}$and $\mathrm{OxyL}^{2-}$ forms, it may be noted that the $\mathrm{p} K_{\mathrm{a}}{ }^{\mathrm{BH}, \text { corr }}\left(\mathrm{S}_{1}\right)$ values for the enol-OxyLH $\mathrm{H}_{2} \rightleftharpoons$ phenolateenol-OxyLH $\left(\sim 4\right.$, reaction V in Figure 5) and enol-OxyLH$H_{2} \rightleftharpoons$ enolate-OxyLH ${ }^{-}(\sim 3$, reaction VI) equilibria support their proposal that the enolic hydroxyl group of enol$\mathrm{OxyLH}_{2}$ is a stronger photoacid than the phenolic hydroxyl group, which indicates that enolate-OxyLH ${ }^{-}$is favored over phenolate-enol-OxyLH ${ }^{-}$in the excited state. ${ }^{[14]}$ Importantly, although this result has no immediate bearing on the excited-state stability of enolate-OxyLH ${ }^{-}$vs. phenolate-keto-OxyLH ${ }^{-}$, these authors were nonetheless able to suggest that the former species is favored over the latter, by observing that the keto form of the HOxyLH analogue can undergo excited-state tautomerization into the enol form in a non-polar basic environment. ${ }^{[14]}$ The reason why this result is not supported by our calculations, yielding as we have seen a $\mathrm{p} K_{\mathrm{E}}{ }^{\mathrm{BH}, \text { corr }}\left(\mathrm{S}_{1}\right)$ of $\sim 6$ for the phenolate-keto$\mathrm{OxyLH}^{-} \rightleftharpoons$ enolate-OxyLH${ }^{-}$equilibrium, is possibly related to the following observation. Namely, assuming that phenolate-keto-OxyLH ${ }^{-}$benefits from having its negative charge distributed between the two oxygen atoms through resonance stabilization (cf. Figure 2), which would be in line with a mechanism put forward to explain why ascorbic acid is $\sim 6$ $\mathrm{p} K$ units more acidic than phenol, ${ }^{[84]}$ it seems natural that the excited-state equilibria of the HOxyLH analogue are somewhat different than those of the "real" $\mathrm{OxyLH}_{2}$ system, 
simply because HOxyLH lacks one of the two proton-generating hydroxyl groups needed for such stabilization. At any rate, a more detailed investigation of this issue would require comparative calculations on the $\mathrm{OxyLH}_{2}$ and $\mathrm{HOxyLH}$ systems beyond the scope of the present paper.

As a further assessment of the present results in light of experimental findings, it may also be noted that $\mathrm{OxyLH}_{2}$ emits at around $550 \mathrm{~nm}$ in aqueous solution. ${ }^{[34]}$ Given that it has been implicated that, in organic solvents, the phenolate-keto-OxyLH ${ }^{-}$form should rather emit at around $600 \mathrm{~nm},{ }^{[23]}$ it is difficult to reconcile with these experimental data our conclusion that phenolate-keto-OxyLH ${ }^{-}$is the dominant species in the excited state in aqueous solution, without invoking the occurrence of a sizable solvatochromic shift. Interestingly, however, such a shift has indeed been observed for the absorption spectra of phenolate-keto-OxyLH ${ }^{-}$isolated in vacuo and complexed with a single water molecule, which was found to induce a blue shift of approximately $50 \mathrm{~nm} \cdot{ }^{[17]}$

Having predicted that the phenolate-keto-OxyLH ${ }^{-}$mono-anion is the preferred form of $\mathrm{OxyLH}_{2}$ in the excited state in aqueous solution, it would be of interest to investigate how the different bulk dielectric environment (hydrophobic rather than polar) offered by the firefly luciferase protein shifts the intrinsic excited-state equilibria of $\mathrm{OxyLH}_{2}$. Such calculations are feasible using hybrid quantum mechanics/molecular mechanics methods, ${ }^{[85]}$ which would also be able to account for the effect of short-ranged specific interactions with the surrounding protein. Although an investigation along those lines is beyond the scope of this work, complementary calculations were nonetheless carried out to obtain estimates of the excited-state $\mathrm{p} K$ values of $\mathrm{OxyLH}_{2}$ in a less polar environment.

These complementary calculations were done in two steps. First, bulk dielectric effects on the results obtained in aqueous solution were assessed by calculating the excited-state $\mathrm{p} K$ values using the same exact $\mathrm{OxyLH}_{2}$ models as before, including 11 explicit water molecules, but with $\varepsilon$ in the SMD treatment lowered from 78.4 (water) to 4.24 (the value for diethylether). Indeed, in the interior of proteins, a value of around 4 is typically assumed. ${ }^{[86]}$ In the second step, noting that the protein binding pocket would not be able to accommodate all of those 11 water molecules, the excited-state $\mathrm{p} K$ values were 
again calculated at $\varepsilon=4.24$, but with only 2 waters (one on either side of $\mathrm{OxyLH}_{2}$ ) and without any water molecule at all.

The results of these calculations are presented in Table S9 of the SI. Notably, since there are no $\mathrm{p} K^{\exp }\left(\mathrm{S}_{0}\right)$ values available for a low-dielectric medium that would enable the estimation of $\mathrm{p} K^{\mathrm{BH} \text {,corr }}\left(\mathrm{S}_{1}\right)$ values by way of Eq. 3, Table $\mathrm{S} 9$ gives "uncorrected" $\mathrm{p} K_{\mathrm{E}}{ }^{\mathrm{BH}}\left(\mathrm{S}_{1}\right)$ and $\mathrm{p} K_{\mathrm{a}}{ }^{\mathrm{BH}}\left(\mathrm{S}_{1}\right)$ values. Interestingly, for all three models of a less polar environment $(11,2$, or 0 water molecules with $\varepsilon=4.24)$ than that offered by our model aqueous solution ( 11 water molecules with $\varepsilon=78.4$ ), phenolate-keto-OxyLH ${ }^{-}$remains the most stable excited-state species, which, loosely speaking, is consistent with a number of previous studies that have identified this form as the chief contributor to the in vivo emission. ${ }^{[12,24,26-29]}$ However, the margins with which phenolate-keto-OxyLH ${ }^{-}$is favored over other species are smaller than in aqueous solution. Particularly, the keto$\mathrm{OxyLH}_{2} \rightleftharpoons$ phenolate-keto-OxyLH${ }^{-}$equilibrium is shifted toward keto-OxyLH $\mathrm{H}_{2}$ (but still favors phenolate-keto-OxyLH ${ }^{-}$) by in total $3.6+1.6=5.2 \mathrm{p} K$ units when $\varepsilon$ is lowered from 78.4 to 4.24 and the number of water molecules is reduced from 11 to 0 . The phenolate-keto-OxyLH ${ }^{-} \rightleftharpoons$ enolate-OxyLH ${ }^{-}$equilibrium, in turn, is correspondingly shifted toward enolate-OxyLH ${ }^{-}$(but still favors phenolate-keto-OxyLH ${ }^{-}$) by in total $4.8+$ $0.2=5.0 \mathrm{p} K$ units.

Finally, it is worthwhile to briefly explore why phenolate-keto-OxyLH $\mathrm{LH}^{-}$is the most stable form of $\mathrm{OxyLH}_{2}$ in the excited state. In Tables S11-S13 of the SI, we summarize an analysis of changes in bond lengths in the excited states relative to the ground states of the different forms that offers some insight into this issue. Namely, from these results it can be inferred that it is the excited state of phenolate-keto-OxyLH ${ }^{-}$that best maintains the stabilizing inter-ring conjugation present in the ground state of each form (cf. Figure 2). One indicator of such a scenario is the inter-ring carbon-carbon bond, which does not change much in the excited state of phenolate-keto-OxyLH ${ }^{-}$, but is pronouncedly shortened in the excited states of all other species: keto-OxyLH $\mathrm{H}_{2}$ (by 0.04 $\AA)$, enol-OxyLH $2(0.07 \AA)$, phenolate-enol-OxyLH ${ }^{-}(0.04 \AA)$, enolate-OxyLH ${ }^{-}(0.04 \AA)$ and $\mathrm{OxyL}^{2-}(0.06 \AA)$. Thus, while phenolate-keto-OxyLH ${ }^{-}$seems capable of preserving the inter-ring conjugation in the excited state, as indicated by the "inertness" of its interring bond to excitation, the other forms do this less well. In this way, one may argue that 
the excited-state stabilization that the other forms should experience through the shortening of the inter-ring bond, is offset by less efficient conjugation between the rings.

\section{Conclusions}

We have calculated excited-state keto-enol and acid-base equilibrium constants connecting six neutral, mono-anionic and di-anionic forms of $\mathrm{OxyLH}_{2}$ in aqueous solution from a $\mathrm{BH}$ cycle using DFT methods in combination with a hybrid clustercontinuum approach to model solvent effects. Thereby, we have tried to establish whether any of these forms is intrinsically more stable in the excited state than the others, which would suggest a potential key role for such a form in the light emission of firefly.

First, from benchmark calculations on phenol, it is inferred that at least ten explicit water molecules are needed to properly model the interactions of $\mathrm{OxyLH}_{2}$ with the aqueous medium, and that $\omega \mathrm{B} 97 \mathrm{X}-\mathrm{D}$ is a suitable choice of density functional for the associated $\mathrm{p} K$ calculations. Indeed, $\omega \mathrm{B} 97 \mathrm{X}-\mathrm{D}$ reproduces the experimental $\mathrm{p} K_{\mathrm{a}}\left(\mathrm{S}_{0}\right)$ and $\Delta \mathrm{p} K_{\mathrm{a}}\left(\mathrm{S}_{1}\right)$ values of phenol with an accuracy of about $1 \mathrm{p} K$ unit.

Second, exploring the possibility that the calculation of excited-state $\mathrm{p} K$ values can be simplified by the use of the Förster equation in place of a BH cycle, it is found that while this standard approximation works quite well for phenol, it generally impacts the results for the $\mathrm{OxyLH}_{2}$ system in a non-negligible fashion. For example, the $\Delta \mathrm{p} K\left(\mathrm{~S}_{1}\right)$ Förster values based on the calculation of vertical excitation energies deviate by up to 2.8 $\mathrm{p} K$ units from the corresponding $\mathrm{BH}$ values. Thus, our choice to include geometricrelaxation and entropic effects in the calculation of the excited-state $\mathrm{p} K$ values of $\mathrm{OxyLH}_{2}$ seems appropriate.

Third, validating our computational protocol relative to experimental reference data, it is demonstrated that both absorption maxima and ground-state $\mathrm{p} K$ values are accurately reproduced, but also emphasized that this in part is likely to be due to cancellation of errors. Specifically, calculated and experimental absorption shifts in aqueous solution between the six forms of the $\mathrm{OxyLH}_{2}$ system consistently agree to within 0.05 (keto-enol forms) and $0.12 \mathrm{eV}$ (acid-base forms). Similarly, for two of the 
three $\mathrm{OxyLH}_{2}$ equilibria for which ground-state $\mathrm{p} K$ values have been measured experimentally, the corresponding calculated values are less than $1 \mathrm{p} K$ unit larger.

Finally, using the validated computational protocol, it is predicted that the phenolate-keto-OxyLH ${ }^{-}$mono-anion is the preferred chemical form of $\mathrm{OxyLH}_{2}$ in the excited state in aqueous solution, and suggested that - albeit with a smaller margin to competing species - this is also the most stable species in a less polar bulk dielectric environment thought to resemble the environment afforded by the firefly luciferase protein. 


\section{Supporting Information}

Additional Supporting Information (Tables S1-S13, Figures S1-S7, and a description of how missing $\mathrm{p} K^{\exp }\left(\mathrm{S}_{0}\right)$ values were estimated) can be found in the online version of this article.

\section{Author Contributions}

The authors contributed equally to all parts of the project.

\section{Acknowledgments}

This work was supported by Linköping University, the Swedish Research Council, the

Olle Engkvist Foundation and the Wenner-Gren Foundations. All calculations were performed at the National Supercomputer Centre (NSC) in Linköping. 


\section{References}

[1] F. McCapra, Acc. Chem. Res. 1976, 9, 201-208.

[2] J. W. Hastings, J. Mol. Evol. 1983, 19, 309-321.

[3] S. H. D. Haddock, M. A. Moline, J. F. Case, Annu. Rev. Mar. Sci. 2010, 2, 443-493.

[4] V. R. Viviani, in CRC Handbook of Organic Photochemistry and Photobiology, Third Edition; A. Griesbeck, M. Oelgemöller, F. Ghetti, Eds.; CRC Press, Boca Raton, FL, 2012; Vol. 2, Chapter 54, pp 1265-1287.

[5] O. Shimomura, in Bioluminescence: Chemical Principles and Methods, Revised Edition; World Scientific, Singapore, 2012.

[6] A. Roda, P. Pasini, M. Mirasoli, E. Michelini, M. Guardigli, Trends Biotechnol. 2004, $22,295-303$.

[7] T. Wilson, J. W. Hastings, Annu. Rev. Cell Dev. Biol. 1998, 14, 197-230.

[8] C. H. Contag, M. H. Bachmann, Annu. Rev. Biomed. Eng. 2002, 4, 235-260.

[9] A. Roda, M. Guardigli, Anal. Bioanal. Chem. 2012, 402, 69-76.

[10] Y. Ando, K. Niwa, N. Yamada, T. Enomoto, T. Irie, H. Kubota, Y. Ohmiya, H. Akiyama, Nat. Photonics 2008, 2, 44-47.

[11] L. Pinto da Silva, J. C. G. Esteves da Silva, J. Comput. Chem. 2011, 32, 2654-2663.

[12] C.-I. Song, Y. M. Rhee, J. Am. Chem. Soc. 2011, 133, 12040-12049.

[13] J. A. Sundlov, D. M. Fontaine, T. L. Southworth, B. R. Branchini, A. M. Gulick, Biochemistry 2012, 51, 6493-6495.

[14] K. M. Solntsev, S. P. Laptenok, P. Naumov, J. Am. Chem. Soc. 2012, 134, 1645216455.

[15] I. Navizet, D. Roca-Sanjuán, L. Yue, Y.-J. Liu, N. Ferré, R. Lindh, Photochem. Photobiol. 2013, 89, 319-325.

[16] L. Pinto da Silva, A. J. M. Santos, J. C. G. Esteves da Silva, J. Phys. Chem. A 2013, $117,94-100$.

[17] K. Støchkel, C. Nygaard Hansen, J. Houmøller, L. Munksgaard Nielsen, K. Anggara, M. Linares, P. Norman, F. Nogueira, O. V. Maltsev, L. Hintermann, S. Brøndsted Nielsen, P. Naumov, B. F. Milne, J. Am. Chem. Soc. 2013, 135, 6485-6493. 
[18] M. Rebarz, B.-M. Kukovec, O. V. Maltsev, C. Ruckebusch, L. Hintermann, P. Naumov, M. Sliwa, Chem. Sci. 2013, 4, 3803-3809.

[19] M. Hiyama, H. Akiyama, K. Yamada, N. Koga, Photochem. Photobiol. 2014, 90, $35-44$.

[20] H. Fraga, Photochem. Photobiol. Sci. 2008, 7, 146-158.

[21] S. M. Marques, J. C. G. Esteves da Silva, IUBMB Life 2009, 61, 6-17.

[22] J. C. G. Esteves da Silva, J. M. C. S. Magalhães, R. Fontes, Tetrahedron Lett. 2001, $42,8173-8176$.

[23] P. Naumov, Y. Ozawa, K. Ohkubo, S. Fukuzumi, J. Am. Chem. Soc. 2009, 131, $11590-11605$.

[24] S. F. Chen, Y.-J. Liu, I. Navizet, N. Ferré, W.-H. Fang, R. Lindh, J. Chem. Theory Comput. 2011, 7, 798-803.

[25] S. Hosseinkhani, Cell. Mol. Life Sci. 2011, 68, 1167-1182.

[26] N. Nakatani, J.-Y. Hasegawa, H. Nakatsuji, J. Am. Chem. Soc. 2007, 129, 87568765 .

[27] B. R. Branchini, M. H. Murtiashaw, R. A. Magyar, N. C. Portier, M. C. Ruggiero, J. G. Stroh, J. Am. Chem. Soc. 2002, 124, 2112-2113.

[28] B. R. Branchini, T. L. Southworth, M. H. Murtiashaw, R. A. Magyar, S. A. Gonzalez, M. C. Ruggiero, J. G. Stroh, Biochemistry 2004, 43, 7255-7262.

[29] T. Hirano, Y. Hasumi, K. Ohtsuka, S. Maki, H. Niwa, M. Yamaji, D. Hashizume, J. Am. Chem. Soc. 2009, 131, 2385-2396.

[30] E. H. White, D. F. Roswell, Photochem. Photobiol. 1991, 53, 131-136.

[31] E. E. Dahlke, C. J. Cramer, J. Phys. Org. Chem. 2003, 16, 336-347.

[32] Z.-W. Li, A.-M. Ren, J.-F. Guo, T. Yang, J. D. Goddard, J.-K. Feng, J. Phys. Chem. A 2008, 112, 9796-9800.

[33] L. Pinto da Silva, J. C. G. Esteves da Silva, ChemPhysChem 2011, 12, 3002-3008.

[34] Y. Erez, I. Presiado, R. Gepshtein, L. Pinto da Silva, J. C. G. Esteves da Silva, D. Huppert, J. Phys. Chem. A 2012, 116, 7452-7461.

[35] M. Hiyama, H. Akiyama, Y. Wang, N. Koga, Chem. Phys. Lett. 2013, 577, 121-126.

[36] C. Scharnagl, R. A. Raupp-Kossmann, J. Phys. Chem. B 2004, 108, 477-489.

[37] F. Eckert, A. Klamt, J. Comput. Chem. 2006, 27, 11-19. 
[38] O. A. Borg, B. Durbeej, J. Phys. Chem. B 2007, 111, 11554-11565.

[39] D. Jacquemin, E. A. Perpète, I. Ciofini, C. Adamo, J. Phys. Chem. A 2008, 112, 794-796.

[40] F. Eckert, I. Leito, I. Kaljurand, A. Kütt, A. Klamt, M. Diedenhofen, J. Comput. Chem. 2009, 30, 799-810.

[41] M. S. Baranov, K. A. Lukyanov, A. O. Borissova, J. Shamir, D. Kosenkov, L. V. Slipchenko, L. M. Tolbert, I. V. Yampolsky, K. M. Solntsev, J. Am. Chem. Soc. 2012, $134,6025-6032$.

[42] T. Förster, Z. Elektrochem. 1950, 54, 42-46.

[43] E. L. Wehry, L. B. Rogers, J. Am. Chem. Soc. 1965, 87, 4234-4238.

[44] Y. Houari, D. Jacquemin, A. D. Laurent, Chem. Phys. Lett. 2013, 583, 218-221.

[45] Y. Houari, D. Jacquemin, A. D. Laurent, Phys. Chem. Chem. Phys. 2013, 15, $11875-11882$.

[46] J. R. Pliego, Jr., J. M. Riveros, J. Phys. Chem. A 2002, 106, 7434-7439.

[47] C. P. Kelly, C. J. Cramer, D. G. Truhlar, J. Phys. Chem. A 2006, 110, 2493-2499.

[48] J. Ho, M. L. Coote, J. Chem. Theory Comput. 2009, 5, 295-306.

[49] J. Ho, M. L. Coote, Theor. Chem. Acc. 2010, 125, 3-21.

[50] A. V. Marenich, W. Ding, C. J. Cramer, D. G. Truhlar, J. Phys. Chem. Lett. 2012, 3, $1437-1442$.

[51] M. J. Frisch, G. W. Trucks, H. B. Schlegel, G. E. Scuseria, M. A. Robb, J. R. Cheeseman, G. Scalmani, V. Barone, B. Mennucci, G. A. Petersson, H. Nakatsuji, M. Caricato, X. Li, H. P. Hratchian, A. F. Izmaylov, J. Bloino, G. Zheng, J. L. Sonnenberg, M. Hada, M. Ehara, K. Toyota, R. Fukuda, J. Hasegawa, M. Ishida, T. Nakajima, Y. Honda, O. Kitao, H. Nakai, T. Vreven, J. A. Montgomery, Jr., J. E. Peralta, F. Ogliaro, M. Bearpark, J. J. Heyd, E. Brothers, K. N. Kudin, V. N. Staroverov, R. Kobayashi, J. Normand, K. Raghavachari, A. Rendell, J. C. Burant, S. S. Iyengar, J. Tomasi, M. Cossi, N. Rega, J. M. Millam, M. Klene, J. E. Knox, J. B. Cross, V. Bakken, C. Adamo, J. Jaramillo, R. Gomperts, R. E. Stratmann, O. Yazyev, A. J. Austin, R. Cammi, C. Pomelli, J. W. Ochterski, R. L. Martin, K. Morokuma, V. G. Zakrzewski, G. A. Voth, P. Salvador, J. J. Dannenberg, S. Dapprich, A. D. Daniels, Ö. Farkas, J. B. Foresman, J. V. Ortiz, J. Cioslowski, D. J. Fox, Gaussian 09, Revision B.01, Gaussian, Inc.: Wallingford CT, 2009. 
[52] T. Nakatsu, S. Ichiyama, J. Hiratake, A. Saldanha, N. Kobashi, K. Sakata, H. Kato, Nature 2006, 440, 372-376.

[53] A. V. Marenich, C. J. Cramer, D. G. Truhlar, J. Phys. Chem. B 2009, 113, 63786396.

[54] R. C. Guedes, B. J. Costa Cabral, J. A. Martinho Simões, H. P. Diogo, J. Phys. Chem. A 2000, 104, 6062-6068.

[55] J. R. Pliego, Jr., J. M. Riveros, J. Phys. Chem. A 2001, 105, 7241-7247.

[56] H. M. Lee, P. Tarkeshwar, K. S. Kim, J. Chem. Phys. 2004, 121, 4657-4664.

[57] M. D. Tissandier, K. A. Cowen, W. Y. Feng, E. Gundlach, M. H. Cohen, A. D. Earhart, J. V. Coe, T. R. Tuttle, Jr., J. Phys. Chem. A 1998, 102, 7787-7794.

[58] M. D. Liptak, G. C. Shields, J. Am. Chem. Soc. 2001, 123, 7314-7319.

[59] R. Bauernschmitt, R. Ahlrichs, Chem. Phys. Lett. 1996, 256, 454-464.

[60] M. E. Casida, C. Jamorski, K. C. Casida, D. R. Salahub, J. Chem. Phys. 1998, 108, $4439-4449$.

[61] R. E. Stratmann, G. E. Scuseria, M. J. Frisch, J. Chem. Phys. 1998, 109, 8218-8224.

[62] M. A. L. Marques, E. K. U. Gross, Annu. Rev. Phys. Chem. 2004, 55, 427-455.

[63] A. Dreuw, M. Head-Gordon, Chem. Rev. 2005, 105, 4009-4037.

[64] M. E. Casida, J. Mol. Struct.: THEOCHEM 2009, 914, 3-18.

[65] C. Lee, W. Yang, R. G. Parr, Phys. Rev. B 1988, 37, 785-789.

[66] A. D. Becke, J. Chem. Phys. 1993, 98, 5648-5652.

[67] P. J. Stephens, F. J. Devlin, C. F. Chabalowski, M. J. Frisch, J. Phys. Chem. 1994, $98,11623-11627$.

[68] Y. Zhao, D. G. Truhlar, Theor. Chem. Acc. 2008, 120, 215-241.

[69] H. Iikura, T. Tsuneda, T. Yanai, K. Hirao, J. Chem. Phys. 2001, 115, 3540-3544.

[70] T. Yanai, D. P. Tew, N. C. Handy, Chem. Phys. Lett. 2004, 393, 51-57.

[71] J.-D. Chai, M. Head-Gordon, J. Chem. Phys. 2008, 128, 084106.

[72] J.-D. Chai, M. Head-Gordon, Phys. Chem. Chem. Phys. 2008, 10, 6615-6620.

[73] C. Van Caillie, R. D. Amos, Chem. Phys. Lett. 1999, 308, 249-255.

[74] C. Van Caillie, R. D. Amos, Chem. Phys. Lett. 2000, 317, 159-164.

[75] F. Furche, R. Ahlrichs, J. Chem. Phys. 2002, 117, 7433-7447. 
[76] G. Scalmani, M. J. Frisch, B. Mennucci, J. Tomasi, R. Cammi, V. Barone, J. Chem. Phys. 2006, 124, 094107.

[77] M. Caricato, B. Mennucci, J. Tomasi, F. Ingrosso, R. Cammi, S. Corni, G. Scalmani, J. Chem. Phys. 2006, 124, 124520.

[78] M. Uppsten, B. Durbeej, J. Comput. Chem. 2012, 33, 1892-1901.

[79] C. Fang, B. Oruganti, B. Durbeej, J. Phys. Chem. A 2014, 118, 4157-4171.

[80] C. J. Cramer, in Essentials of Computational Chemistry: Theories and Models, Second Edition; Wiley, Chichester, UK, 2004.

[81] A. I. Biggs, R. A. Robinson, J. Chem. Soc. 1961, 388-

[82] J. Aragó, J. C. Sancho-García, E. Ortí, D. Beljonne, J. Chem. Theory Comput. 2011, 7, 2068-2077.

[83] O. V. Maltsev, N. K. Nath, P. Naumov, L. Hintermann, Angew. Chem. Int. Ed. 2014, $53,847-850$.

[84] M. M. Taqui Khan, A. E. Martell, J. Am. Chem. Soc. 1967, 89, 7104-7111.

[85] H. M. Senn, W. Thiel, Angew. Chem. Int. Ed. 2009, 48, 1198-1229.

[86] M. R. A. Blomberg, P. E. M. Siegbahn, G. T. Babcock, J. Am. Chem. Soc. 1998, 120, $8812-8824$. 


\begin{tabular}{|c|c|c|}
\hline Method & $\mathrm{p} K_{\mathrm{a}}^{\mathrm{BH}}\left(\mathrm{S}_{0}\right)$ & $\Delta \mathrm{p} K_{\mathrm{a}}^{\mathrm{F}, \mathrm{exc}+\mathrm{emi}}\left(\mathrm{S}_{1}\right)$ \\
\hline B3LYP & 9.86 & -7.29 \\
\hline M06 & 8.21 & -7.67 \\
\hline LC-BLYP & 6.32 & -7.47 \\
\hline CAM-B3LYP & 8.27 & -7.92 \\
\hline$\omega B 97 X$ & 8.52 & -7.14 \\
\hline$\omega \mathrm{B} 97 \mathrm{X}-\mathrm{D}$ & 9.60 & -7.12 \\
\hline $\mathrm{HF} / \mathrm{CIS}$ & 15.84 & -9.14 \\
\hline $\operatorname{Exp}^{[\mathrm{b}]}$ & 10.00 & -6.00 \\
\hline
\end{tabular}


Table 2. $\Delta \mathrm{p} K_{\mathrm{a}}\left(\mathrm{S}_{1}\right)$ values of phenol calculated with Förster and BH cycles. ${ }^{[\mathrm{a}]}$

\begin{tabular}{lcccc|} 
& \multicolumn{4}{c}{ Method } \\
\cline { 2 - 5 } Cycle & B3LYP & $\omega B 97 X$ & $\omega B 97 X-D$ & Exp. $^{[b]}$ \\
\hline$\Delta \mathrm{p} K_{\mathrm{a}}^{\mathrm{F}, \text { exc }}\left(\mathrm{S}_{1}\right)$ & -5.92 & -5.44 & -5.34 & -4.31 \\
$\Delta \mathrm{p} K_{\mathrm{a}}^{\mathrm{F}, \text {,emi }}\left(\mathrm{S}_{1}\right)$ & -8.67 & -8.84 & -8.90 & -7.77 \\
$\Delta \mathrm{p} K_{\mathrm{a}}^{\mathrm{F}, \text {,exc+emi }}\left(\mathrm{S}_{1}\right)$ & -7.29 & -7.14 & -7.12 & -6.00 \\
$\Delta \mathrm{p} K_{\mathrm{a}}^{\mathrm{F}, \text { adia }}\left(\mathrm{S}_{1}\right)$ & -7.07 & -6.89 & -6.63 & - \\
$\Delta \mathrm{p} K_{\mathrm{a}}^{\mathrm{F}, 0-0}\left(\mathrm{~S}_{1}\right)$ & -6.40 & -6.42 & -6.23 & - \\
$\Delta \mathrm{p} K_{\mathrm{a}}^{\mathrm{BH}}\left(\mathrm{S}_{1}\right)$ & - & -5.64 & -5.69 & - \\
\hline
\end{tabular}

[a] All calculations carried out with the $6-31+\mathrm{G}(\mathrm{d}, \mathrm{p})$ basis set and six explicit water molecules.

[b] Experimental values from Ref. 43. 


\begin{tabular}{|c|c|c|c|}
\hline Cycle & MSE & RMSD & MAD \\
\hline$\Delta \mathrm{p} K^{\mathrm{F}, \operatorname{exc}}\left(\mathrm{S}_{1}\right)$ & -0.59 & 1.70 & 2.77 \\
\hline$\Delta \mathrm{p} K^{\mathrm{F}, \mathrm{emi}}\left(\mathrm{S}_{1}\right)$ & -0.44 & 1.94 & 3.57 \\
\hline$\Delta \mathrm{p} K^{\mathrm{F}, \mathrm{exc}+\mathrm{emi}}\left(\mathrm{S}_{1}\right)$ & -0.51 & 1.32 & 2.95 \\
\hline$\Delta \mathrm{p} K^{\mathrm{F}, \text { adia }}\left(\mathrm{S}_{1}\right)$ & -0.43 & 0.97 & 2.04 \\
\hline$\Delta \mathrm{p} K^{\mathrm{F}, 0-0}\left(\mathrm{~S}_{1}\right)$ & -0.52 & 1.47 & 3.10 \\
\hline
\end{tabular}




\begin{tabular}{|c|c|c|c|}
\hline \multirow[b]{2}{*}{ Equilibrium reaction } & \multirow[b]{2}{*}{ Type } & \multicolumn{2}{|c|}{ Absorption shift ${ }^{[b]}$} \\
\hline & & Calculated & $\operatorname{Exp}^{[\mathrm{c}]}$ \\
\hline keto-OxyLH $\mathrm{O}_{2} \rightleftharpoons$ enol-OxyLH ${ }_{2}$ & keto-enol & 0.14 & 0.19 \\
\hline $\begin{array}{l}\text { phenolate-keto-OxyLH }{ }^{-} \rightleftharpoons \text { phenolate-enol- } \\
\text { OxyLH }^{-}\end{array}$ & keto-enol & 0.46 & 0.51 \\
\hline keto-OxyLH ${ }_{2} \rightleftharpoons$ phenolate-keto-OxyLH ${ }^{-}$ & acid-base & -0.52 & -0.64 \\
\hline enol-OxyLH ${ }_{2} \rightleftharpoons$ phenolate-enol-OxyLH ${ }^{-}$ & acid-base & -0.20 & -0.32 \\
\hline enol-OxyLH ${ }_{2} \rightleftharpoons$ enolate-OxyLH ${ }^{-}$ & acid-base & -0.29 & -0.38 \\
\hline phenolate-enol-OxyLH ${ }^{-} \rightleftharpoons \mathrm{OxyL}^{2-}$ & acid-base & -0.15 & -0.14 \\
\hline enolate-OxyLH ${ }^{-} \rightleftharpoons \mathrm{OxyL}^{2-}$ & acid-base & -0.06 & -0.08 \\
\hline \multicolumn{4}{|c|}{$\begin{array}{l}\text { [a] All calculations carried out at the } \omega \mathrm{B} 97 \mathrm{X}-\mathrm{D} / 6-31+\mathrm{G}(\mathrm{d}, \mathrm{p}) \text { level of theory and with } 11 \\
\text { explicit water molecules. }\end{array}$} \\
\hline \multicolumn{4}{|c|}{$\begin{array}{l}\text { [b] Absorption maxima obtained as vertical } \mathrm{S}_{0} \rightarrow \mathrm{S}_{1} \text { excitation energies and absorption } \\
\text { shifts evaluated relative to the left-hand sides of the equilibria. } \\
\text { [c] Experimental values from Ref. } 18 \text {. }\end{array}$} \\
\hline
\end{tabular}




\begin{tabular}{|c|c|c|c|}
\hline \multicolumn{4}{|c|}{ Table 5. Calculated $\mathrm{p} K_{\mathrm{E}}{ }^{\mathrm{BH}}\left(\mathrm{S}_{0}\right)$ and $\mathrm{p} K_{\mathrm{a}}{ }^{\mathrm{BH}}\left(\mathrm{S}_{0}\right)$ values of $\mathrm{OxyLH}_{2}{ }^{[\mathrm{a}]}$} \\
\hline Equilibrium reaction & Type & Calculated & $\operatorname{Exp}^{[\mathrm{b}]}$ \\
\hline nol-OxyLH 2 & keto-enol & 0.48 & -0.39 \\
\hline phenolate-keto-OxyLH ${ }^{-} \rightleftharpoons$ phenolate-enol-OxyLH ${ }^{-}$ & keto-enol & 4.33 & - \\
\hline keto-OxyLH $2 \rightleftharpoons$ phenolate-keto-OxyLH ${ }^{-}$ & acid-base & 4.77 & - \\
\hline enol-OxyLH ${ }_{2} \rightleftharpoons$ phenolate-enol-OxyLH ${ }^{-}$ & acid-base & 8.62 & - \\
\hline enol-OxyLH ${ }_{2} \rightleftharpoons$ enolate-OxyLH ${ }^{-}$ & acid-base & 10.79 & 7.40 \\
\hline phenolate-enol-OxyLH ${ }^{-} \rightleftharpoons \mathrm{OxyL}^{2-}$ & acid-base & 11.61 & - \\
\hline enolate-OxyLH ${ }^{-} \rightleftharpoons \mathrm{OxyL}^{2-}$ & acid-base & 9.44 & 9.10 \\
\hline
\end{tabular}

[a] All calculations carried out at the $\omega B$ 97X-D/6-31+G(d,p) level of theory and with 11 explicit water molecules.

[b] Experimental values from Ref. 18. 


\section{Figure Captions}

Figure 1. Formation of oxyluciferin from D-luciferin.

Figure 2. Chemical structures of different forms of oxyluciferin and the excited-state equilibrium constants for the keto-enol $\left[\mathrm{p} K_{\mathrm{E}}\left(\mathrm{S}_{1}\right)\right]$ and acid-base $\left[\mathrm{p} K_{\mathrm{a}}\left(\mathrm{S}_{1}\right)\right]$ reactions that connect them.

Figure 3. Starting model for the phenolate-keto-OxyLH ${ }^{-}+$water cluster.

Figure 4. $\mathrm{p} K_{\mathrm{a}}{ }^{\mathrm{BH}}\left(\mathrm{S}_{0}\right)$ and $\mathrm{p} K_{\mathrm{a}}{ }^{\mathrm{BH}}\left(\mathrm{S}_{1}\right)$ values of phenol calculated with different numbers of water molecules at the $\omega \mathrm{B} 97 \mathrm{X}-\mathrm{D} / 6-31+\mathrm{G}(\mathrm{d}, \mathrm{p})$ level of theory. The dashed lines indicate the respective average values.

Figure 5. Experimental ground-state and calculated excited-state equilibrium constants for the keto-enol and acid-base reactions of $\mathrm{OxyLH}_{2}$. 

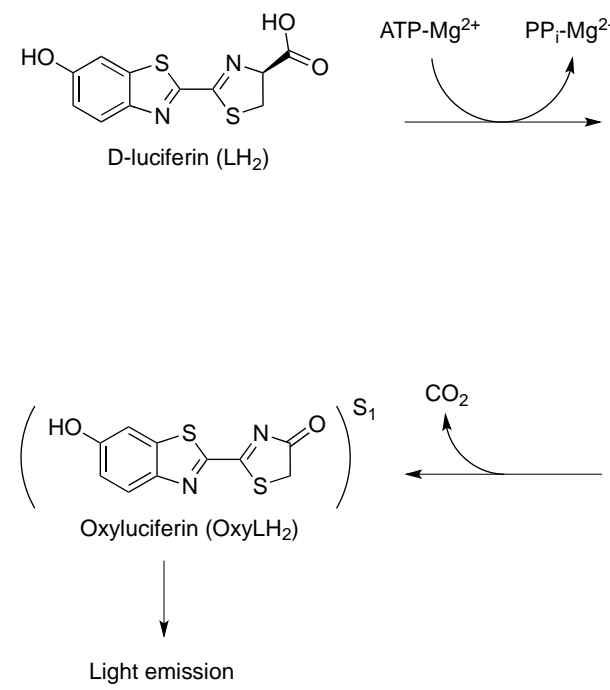
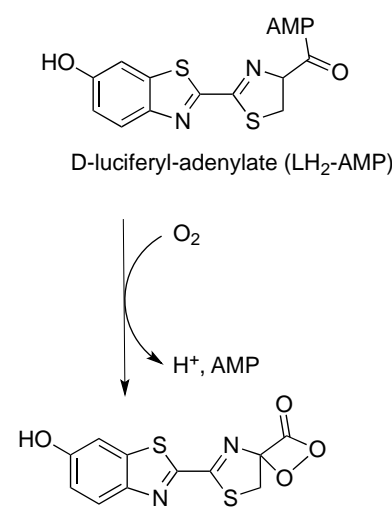

Firefly dioxetanone (Diox)

Figure 1 


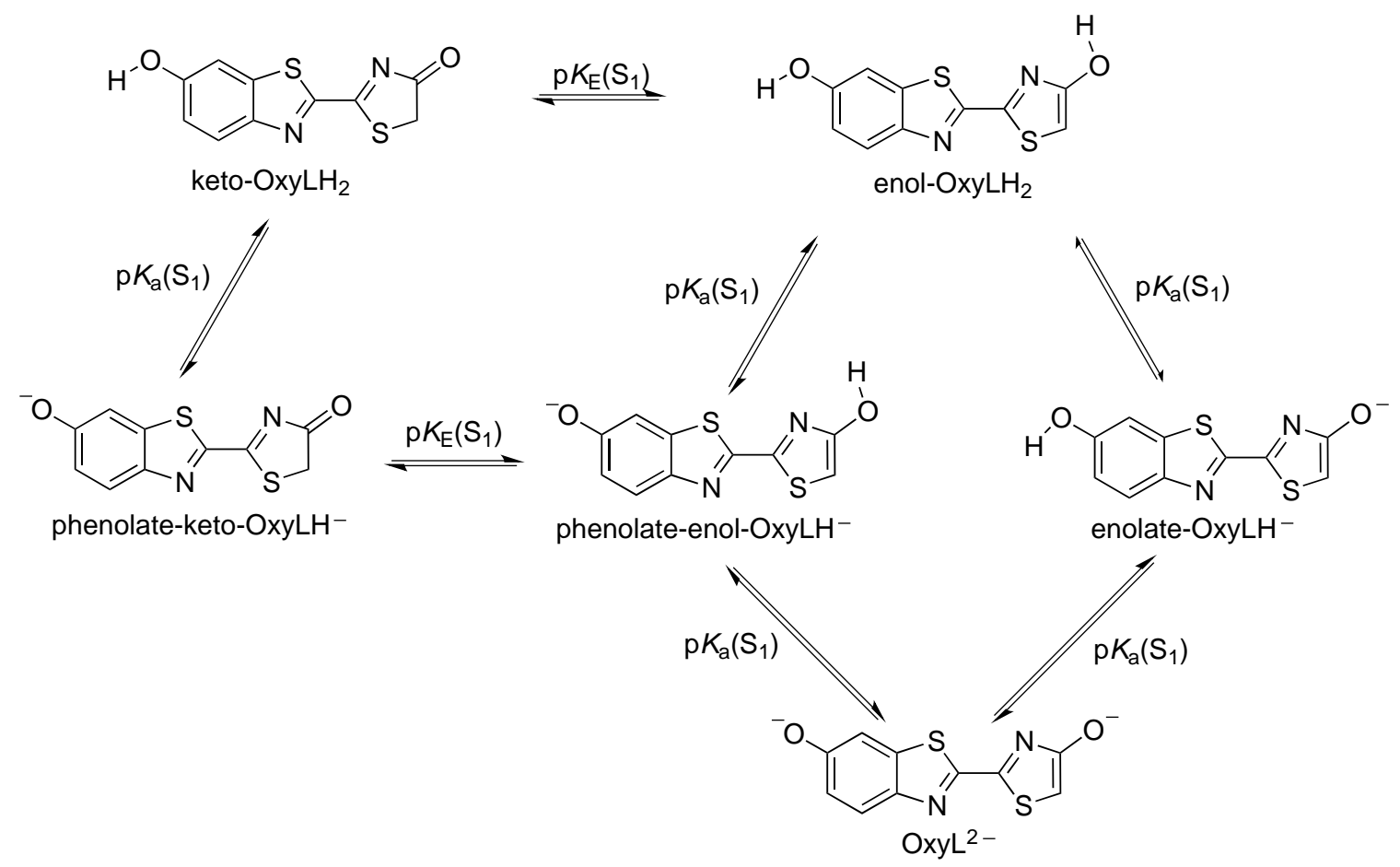

Figure 2 


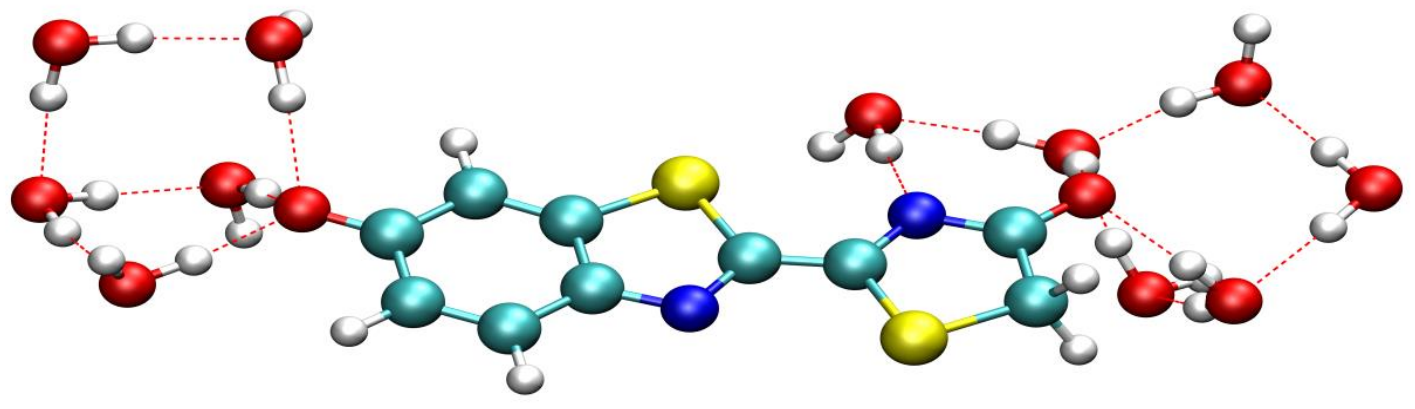

Figure 3 


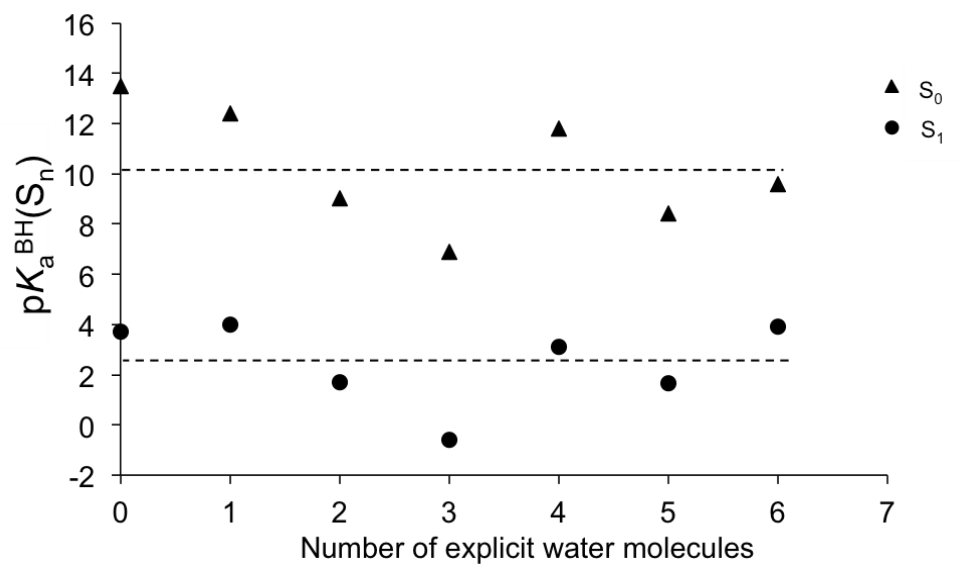

Figure 4 

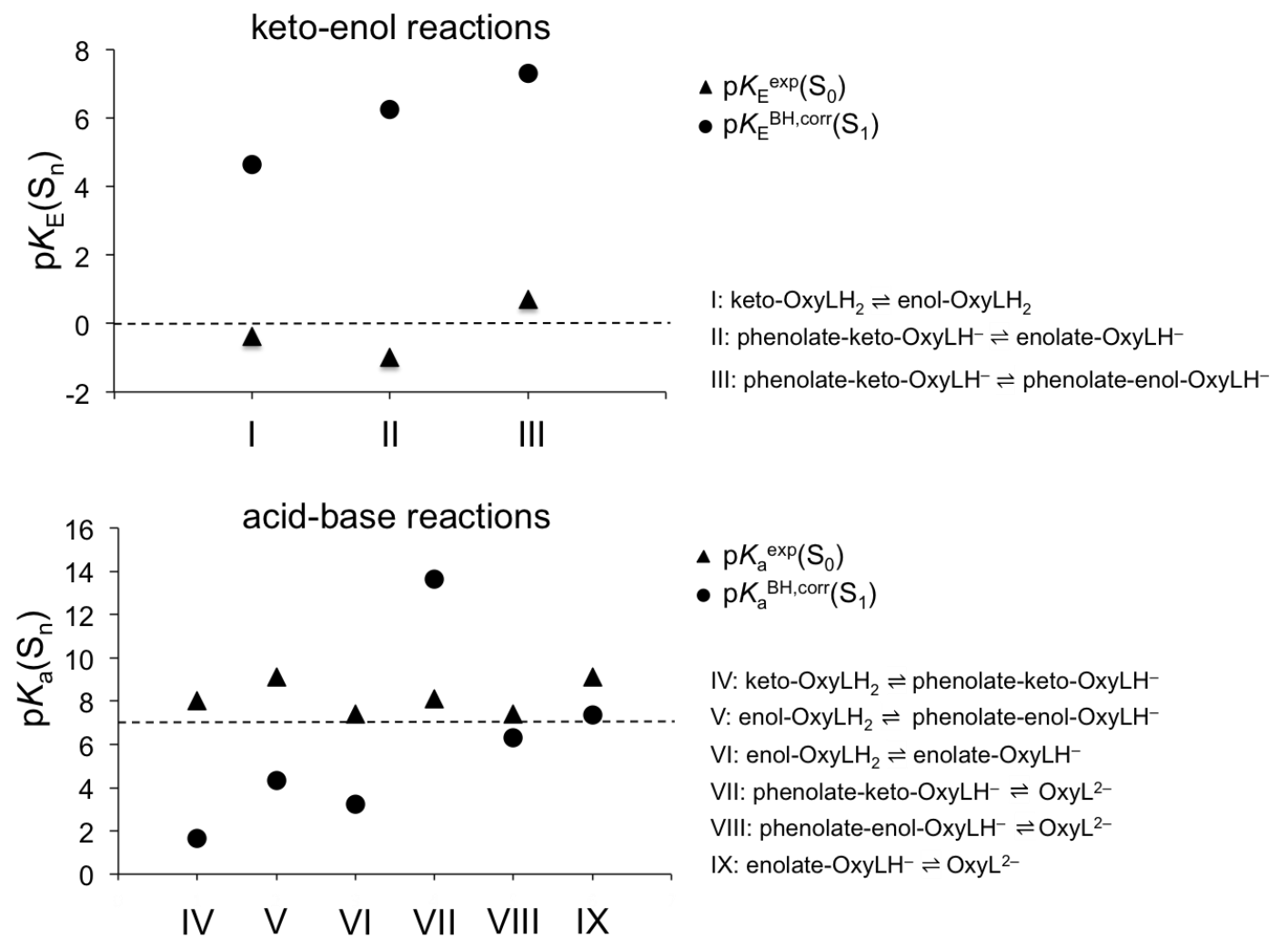

Figure 5 